\title{
Possibilities for Justice and Equity in Human Rights and Climate Law: Benefit-Sharing in Climate Finance
}

\author{
Kim Bouwer \\ The Exeter Law School, University of Exeter, Exeter, United Kingdom \\ k.bouwer@exeter.ac.uk
}

\begin{abstract}
This article examines benefit-sharing in the context of climate finance. Both benefitsharing and climate finance are complex, heterogeneous, and fast-developing fields, where the interaction of international human rights law and climate law can create both clarity and confusion. Benefit-sharing as a means for greater equity and fairness is increasingly used or included in materials on climate finance, despite lacking clear conceptualization in this context. The article does three things. First, it establishes benefit-sharing as an emerging obligation in human rights law and environmental law. Second, it explores how benefit-sharing appears in the climate regime, with a view to determining whether benefit-sharing has a distinct meaning in this context - and, if so, what it is. The article argues that both the meaning and the practice of benefitsharing in climate finance are incoherent. Third, the article interrogates the possibilities and problems of adopting universalized norms of benefit-sharing in this context, and suggests some places where norms might be beneficial.
\end{abstract}

\section{Keywords}

climate finance - international environmental law - international human rights law benefit-sharing - participation 
This article examines fair and equitable benefit-sharing in climate finance law. ${ }^{1}$ The scope and normativity of benefit-sharing, as well as the institutional and regulatory framework of climate finance, are unsettled and continue to change shape. So, the article examines benefit-sharing obligations and practices in relation to project-based finance dispensed through the 'climate funds' (defined below). It borrows from jurisprudence in other areas of environmental law to inform this concept. The broad rationale for this approach is that although benefit-sharing has the potential to support just and equitable outcomes in climate change responses, it remains undefined, so it is hard to discern any clear or definitive guidelines for benefit-sharing in climate finance. In this article I question the relative merits of universal and ad hoc approaches, but nevertheless suggest that the introduction of some universal norms could support a coherent and potentially more just approach to benefit-sharing in climate finance.

While its most significant articulation is in international biodiversity law, benefit-sharing is also used to compensate, reward, or engage various stakeholders in climate adaptation and mitigation activities at the national and subnational levels. ${ }^{2}$ Benefit-sharing is increasingly deployed across the climate change landscape to support reallocation of advantages derived from climate responses. ${ }^{3}$ It is not mentioned in any core climate treaties, but, as discussed below, it could be read into the treaties as a requirement in a number

1 The early research for this article was financially supported with a grant (no. 335592) from the European Research Council under the Benelex Project, run out of Strathclyde Centre for Law and Environmental Governance. It has been generously read by the other members of the Benelex Team, and Annalisa Savaresi, Kati Kulovesi, and Maria Manguiat also provided helpful comments on earlier versions. I am grateful to Alphaeus Ngonga for research assistance. Earlier versions were presented at the Society of Legal Scholars Conference at University College Dublin in 2017, the BeneLex Final Project Meeting, Ross Priory, Scotland in 2018, the IUCN-AEL Symposium at University of Strathclyde, Glasgow in 2018, and the Max Weber Fellows' Law Writers' Group, European University Institute, Florence in 2019. I am grateful to all present for their interest and helpful comments.

2 Annalisa Savaresi, 'The Emergence of Benefit-Sharing under the Climate Regime: A Preliminary Exploration and Research Agenda', University of Edinburgh School of Law Research Paper (Series No. 2014/43), September 2014.

3 Ibid.; and Ademola Oluborode Jegede, The Climate Change Regulatory Framework and Indigenous Peoples' Lands in Africa: Human Rights Implications (Pretoria University Law Press, 2016). However, these also arise in activities contributing to climate change, such as oil-and-gas extraction: see, generally, Lila Barrera-Hernandez, Barry Barton, Lee Godden, Alastair Lucas, and Anita Ronne, 'Introduction: Sharing Costs and Benefits of Energy and Resource Activity', in Lila Barrera-Hernández, Barry Barton, Lee Godden, Alastair Lucas, and Anita Ronne (eds), 
of ways, and in particular through the stipulation that human rights should be respected and the vulnerable should be protected. In theory, benefit-sharing could be employed to carve out spaces for justice and equity in the climate regime, where it could be used to engineer more positive and equitable outcomes in cases where climate responses might embed or worsen existing patterns of inequity. Benefit-sharing could contribute to ensuring that the advantages generated by the responses to climate change are allocated in a fair and equitable manner. ${ }^{4}$

Simultaneously, the adoption of the Paris Agreement, with its introduction of common but differentiated climate commitments for all parties, has brought climate finance into sharp focus. According to the working definition of the UNFCCC's Standing Committee on Finance, 'climate finance' is 'the financial resources dedicated to adapting to and mitigating climate change globally, including in the context of financial flows to developing countries. ${ }^{5}$ The provision of climate finance is an obligation of developed countries, ${ }^{6}$ and parties to the Paris Agreement are committed to making 'finance flows consistent with a pathway towards low greenhouse gas emissions and climate-resilient development.' ${ }^{7}$ For now, the supply, sources, sufficiency, and transparency of climate finance dominate the conversation, and discussions around climate justice and equity tend to address broader questions around ethical responsibility and burden-sharing. Although there is increasing attention on human rights impacts at the recipient end of climate finance, very little attention has been paid to benefit-sharing in climate finance per se. ${ }^{8}$ The prospect (or necessity) of a considerable upswing in climate finance means that questions about justice in climate finance need to be given urgent thought, to ensure that mechanisms in climate finance support rather than undermine the achievement of fairness and equity.

Sharing the Costs and Benefits of Energy and Resource Activity: Legal Change and Impact on Communities (Oxford University Press, 2016).

4 Annalisa Savaresi and Kim Bouwer, 'Equity and Justice in Climate Change Law and Policy: A Role for Benefit-Sharing', in Research Handbook on Climate Justice, edited by Tasneen Jafry (Routledge, 2018).

5 UnfCCC SCF, 2018 Biennial Assessment and Overview of Climate Finance Flows: Technical Report, <https://unfccc.int/sites/default/files/resource/2018\%20BA\%20Technical\%20 Report\%2oFinal.pdf $>$, para. 13. This is not a universally accepted or uncontentious definition, and the absence of a clear definition on climate finance is not accidental: Romain Weikmans, J. Timmons Roberts, and Stacy-Ann Robinson, 'What Counts as Climate Finance? Define Urgently' (2020) 588 Nature 220. This is not, however, an issue that needs to be resolved in this article.

6 Paris Agreement, Article 9.

7 Ibid., Article 2(1)(c).

8 Although see Savaresi, supra note 2. 
This leads to the main question of this article: Is benefit-sharing an existing or emerging norm in international climate law and the international law of climate finance? Subsidiary to this are considerations including what the content of that norm might be, how it resembles or differs from benefit-sharing in other contexts, and whether benefit-sharing in climate finance should have its own characteristics or be subject to ad hoc practice. I aim in this article to answer the main question, and I will offer some reflections on the subsidiary questions, which are difficult to answer definitively.

There are several things that this article does not do. First, regarding methodology, there is much to be gained from a sociological evaluation of the efficacy and equity of benefit-sharing arrangements or other participatory processes in a variety of contexts, but this is a different project from the one undertaken here. A modest textual review was conducted as a scoping exercise. Second, the focus here is very narrowly on the potential to achieve equity and fairness within climate responses, ${ }^{9}$ specifically in relation to benefit-sharing. The effectiveness of these projects (both financially and in terms of climate goals) is of course important, but this is beyond the scope of the article. ${ }^{10}$ Third, the article is focused on the provision of finance through the 'climate funds', viz. the intermediary bodies (outlined in Section 3) established or brought under the climate regime to distribute climate finance, and which purport to employ benefit-sharing in relation to projects in (usually) developing countries. This is a good starting point for this kind of enquiry. Fourth, I do not, therefore, directly consider the funding mechanisms established under the Kyoto Protocol, ${ }^{11}$ the specific benefit-sharing arrangements applicable to forests, ${ }^{12}$ or any arrangements being contemplated under Article 6 of the Paris Agreement. All of these

9 More generally, see Friedrich Soltau, Fairness in International Climate Change Law (Cambridge University Press, 2009).

10 It should be possible to do both. See, however, e.g., Tomilola Eni-ibukun, 'Climate Justice: The Clean Development Mechanism as a Case Study', in Erkki J. Hollo, Kati Kulovesi, and Michael Mehling (eds), Climate Change and the Law (Springer Netherlands, 2013).

11 Specifically, the Clean Development Mechanism. Although see Savaresi, supra note 2, 8-10.

12 There is extensive literature about benefit-sharing in REDD+; see Savaresi and Bouwer, supra note 3, section 3(a); Jegede, supra note 3; Cecilia Luttrell, Lasse Loft, Maria Fern Gebara, Demetrius Kweka, Maria Brockhaus, Arild Angelson, and William Sunderlin, 'Who Should Benefit from REDD+? Rationales and Realities', 18 Ecology and Society $5^{2}$ (2013); Kathleen Birrell and Lee Godden, 'Benefits and Sharing: Realizing Rights in REDD+', 9 Journal of Human Rights and the Environment 6 (2018); Grace Yee Wong, Lasse Loft, Maria Brockhaus, Anastasia Lu Yang, Thu Thuy Pham, Samuel Assembe-Mvondo, and Cecilia Luttrell, 'An Assessment Framework for Benefit Sharing Mechanisms to Reduce Emissions from Deforestation and Forest Degradation within a Forest Policy Mix', 27 Environmental Policy and Governance 436 (2017); Sophie Chapman, Martijn Wilder, and Ilona Miller, 'Defining 
result in financial flows broadly called 'climate finance', but they are governed by specific instruments and require separate consideration on their own merits. ${ }^{13}$ I have used some of the critical literature about these mechanisms to inform my own analysis. ${ }^{14}$

The next section discusses the status of the norm of benefit-sharing in international climate finance law, questioning whether a norm exists and how it is distinct from norms in other areas of international environmental law. Following that, Section 3 explains what is meant by climate finance in this article, and explains where benefit-sharing obligations already exist in the climate funds. Section 4 draws on the jurisprudence discussed in Section 2 to suggest what a developed norm of climate finance might look like, seeking to illustrate where existing practices are helpful, where distinctions need to be made, and where difficulties could be anticipated.

Benefit-Sharing

2.1

\section{Benefit-Sharing in International Environmental Law and Human Rights Law}

Benefit-sharing was developed to ensure that indigenous peoples or local communities with a legal or moral stake in the exploitation of their land, property, or traditional knowledge have a right to share in the benefits derived from these processes. Examples include: profit-sharing in circumstances where indigenous traditional knowledge is exploited commercially, also called bio-prospecting (research and innovation based on genetic resources) ${ }_{i}^{15}$ or ensuring local community access to employment and shareholding opportunities in mining or extractive industries. ${ }^{16}$ Benefit-sharing obligations are becoming ubiquitous in

the Legal Elements of Benefit Sharing in the Context of REDD+', 4 Carbon and Climate Law Review 270 (2014); Julia Dehm, 'Indigenous Peoples and REDD+ Safeguards: Rights as Resistance or as Disciplinary Inclusion in the Green Economy?' (2016) 7 Journal of Human Rights and the Environment 170.

13 Eni-ibukun, supra note 10.

14 Most significantly, Damilola Olawuyi, The Human Rights-Based Approach to Carbon Finance (Cambridge University Press, 2016).

15 See Saskia Vermeylen, 'Contextualizing "Fair" and "Equitable": The San's Reflections on the Hoodia Benefit-Sharing Agreement', 12 Local Environment 423 (2007).

16 Hanri Mostert, Kangwa-Musole Chisanga, Janine Howard, Fatima Mandhu, Meyer van den Berg, and Cheri-Leigh Young, 'Corporate Social Responsibility in the Mining Industries of Namibia, South Africa, and Zambia: Choices and Consequences', in Barrera-Hernández, et al. (eds), supra note 3 . 
international human rights law and in international environmental law, most prominently in international biodiversity law. However, benefit-sharing is still quite incoherent as a concept, and has a mixed track-record in terms of the equity and justice that are the purported aims of these arrangements. The first two subsections deal with these ideas. They draw heavily on the cross-sectoral literature on benefit-sharing, although space does not permit a full elaboration of how benefit-sharing is articulated across the different regimes. The third subsection explores the status and usefulness of benefit-sharing in international climate law. Later, Section 4, relying heavily on the jurisprudence referenced herein, fleshes out the possible content of a norm of benefit-sharing in climate finance.

Benefit-sharing is a positive obligation in some areas of international environmental law and human rights law. The most developed articulation of benefit-sharing, reflecting the rights of indigenous peoples (IP) in international law, appears under the Convention for Biological Diversity. The CBD lays down the rights of IP to benefit-sharing in the use of their traditional knowledge, innovations, and practices relating to nature conservation and bio-prospecting. ${ }^{17}$ The CBD's formulation of benefit-sharing may be considered authoritative; it is well developed through ancillary instruments, specifically the Nagoya Protocol, ${ }^{18}$ as well as the 2004 Akwé: Kon Guidelines on environmental and socio-cultural assessments, ${ }^{19}$ which provide detail on, and support for, the implementation of benefit-sharing under the Nagoya Protocol. ${ }^{20}$ The СвD enjoys high levels of participation and ratification, entailing high levels of consensus - although, as is well known, the United States is not a party. In this context the CBD may be considered complementary to international human rights law, ${ }^{21}$ and perhaps also to other international regimes for the

17 Convention on Biological Diversity 1992, 1760 UnTs 79, Article 8(j).

18 Specifically, the Nagoya Protocol on Access to Genetic Resources and the Fair and Equitable Sharing of Benefits Arising from their Utilization to the Convention on Biological Diversity, 29 October 2010, for the promotion of benefit-sharing from the use of natural resources.

19 Akwe: Kon Guidelines (свD Decision vir/16C(2004) Annex).

20 Global South scholars are more critical; see Jorge Cabrera Medaglia, 'Access and BenefitSharing: North-South Challenges in Implementing the Convention on Biological Diversity and Its Nagoya Protocol', in Shawkat Alam, Attapattu Sumudu, Carmen Gonzalez, and Jona Razzaque (eds), International Environmental Law and the Global South (Cambridge University Press, 2015); Kanchana Kariyawasam and Matthew Tsai, 'Access to Genetic Resources and Benefit Sharing: Implications of Nagoya Protocol on Providers and Users', 21 Journal of World Intellectual Property 289 (2018).

21 Case of the Kalina and Lokono Peoples v. Suriname Merits Reparations and Costs, Judgment, Inter-Am. Ct. H.R. No. 309 (25 Nov. 2015), para. 174 (hereinafter Kalina Case). 
protection of the environment. On the other hand, the vague and voluntary nature of the 2004 Guidelines may be seen as an attempt by CBD parties to limit the international law-making implications of treaty-related guidelines. ${ }^{22}$

In 2018, benefit-sharing was included as a Framework Principle (FP) - one of the core human rights obligations in the environmental context - in the final report of the UN Special Rapporteur on Human Rights and the Environment, John Knox. ${ }^{23}$ In particular, $\mathrm{FP}_{15}$ requires states to ensure the fair and equitable sharing of benefits with indigenous peoples or local communities (IPLC) in relation to use of their lands, territories, or resources, ${ }^{24}$ where 'local communities' refers to traditional communities which do not define themselves as indigenous but have a close relationship with nature and depend on this relationship for material or cultural survival. ${ }^{25}$ The FP s expand on what benefit-sharing should entail, particularly regarding the need for early and proper consultation, ${ }^{26}$ just and fair redress for harm, ${ }^{27}$ and free, prior, and informed consent. ${ }^{28}$ While the FP s are not meant to create new obligations or represent authoritative treaty interpretation, ${ }^{29}$ they are authoritative statements reflecting actual or emerging law. Knox states that the principles reflect 'minimum standards' of protection, should be seen as best practice, and either reflect existing law or should expeditiously and formally be adopted as norms. ${ }^{30}$ The

22 Elisa Morgera, 'Dawn of a New Day? The Evolving Relationship between the Convention on Biological Diversity and International Human Rights Law', 53 Wake Forest Law Review 101 (2018), 119 .

23 John Knox, Report of the Special Rapporteur on the Issue of Human Rights Obligations Relating to the Enjoyment of a Safe, Clean, Healthy and Sustainable Environment, UN General Assembly 2018, A/HRC/37/59, <https://documents-dds-ny.un.org/doc/UNDOC/GEN/ G18/o17/29/PDF/G18o1729.pdf?OpenElement>.

24 Ibid., Principle 15, para. (d). FP 15 protects the rights of indigenous people and traditional communities, and further emphasizes the need to respect their rights and interests, the importance of free, prior, and informed consent being obtained through consultation when their rights are affected, and the importance of respecting their traditional knowledge and practices.

25 Knox, supra note 23, para. 48. The paragraph continues: 'Examples include the descendants of Africans brought to Latin America as slaves, who escaped and formed tribal communities. To protect the human rights of the members of such traditional communities, States owe them obligations as well. While those obligations are not always identical to those owed to indigenous peoples, they should include the obligations described below' (see A/HRC/34/49,

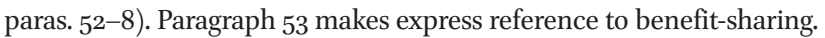

26 Ibid., FP 9.

27 Ibid., paras 51-3.

28 Ibid., FP 15 (b).

29 Morgera, supra note 22.

30 Knox, supra note 23, paras 8-9. 
inclusion of benefit-sharing in the FP s reflects the status of benefit-sharing as a principle of international human rights law (discussed below), as well as the treaty-based recognition of indigenous peoples' human rights, in particular under ILO Convention $169 .{ }^{31}$ The FP s recognize that not all states have ratified the underlying treaties; nevertheless, they were considered by Knox to be sufficiently broadly accepted by international bodies and reflected in state practice to constitute established norms. ${ }^{32}$

It is notable that, despite these authoritative statements supporting benefit-sharing in international human rights law, Knox had to rely heavily on the CBD and associated guidance to flesh out the detail of what is required for fair and equitable benefit-sharing. Benefit-sharing has also been applied directly or interpreted as an obligation in decisions of the Inter-American Court of Human Rights, ${ }^{33}$ and the Court's jurisprudence favours reliance on guidance adopted under the CBD to support understandings of benefit-sharing in human rights law and natural resources law. ${ }^{34}$ This makes sense when the obligations on benefit-sharing in human rights law are subjected to further examination: on the whole they are quite abstract and yield little guidance on practical application. ${ }^{35}$ This is probably the reason for Knox's careful framing of benefit-sharing as an 'emerging' principle of international law.

Benefit-sharing arrangements also appear in connection with the exploitation and measures for the conservation of natural resources such as water, ${ }^{36}$ and in connection with agriculture (for instance in relation to seed-resilience schemes), ${ }^{37}$ energy projects, and extractive activities. ${ }^{38}$ While these frameworks indicate that benefit-sharing is required in specific contexts, they do not contain the level of detail on substance or procedure developed under the

31 International Labour Organization, Indigenous and Tribal Peoples Convention, 1989 (No. 169) Convention concerning Indigenous and Tribal Peoples in Independent Countries, Article 15 .

Knox, supra note 23, para. 9 .

Ibid., 193. Also see Elisa Morgera, 'Under the Radar: The Role of Fair and Equitable BenefitSharing in Protecting and Realising Human Rights Connected to Natural Resources', 7 The International Journal of Human Rights 1098 (2019).

35 Ibid.

36 Ramsar Convention on Wetlands of International Importance, Resolution X.19: Wetlands and River Basin Management: Consolidated Scientific and Technical Guidance (2008), Annex, para. 25.

37 Food and Agriculture Organization, Voluntary Guidelines on the Responsible Governance of Tenure of Land, Fisheries and Forests in the Context of National Food Security (VGGT), UN Doc. CL 144/9 (C 2013/20) (2012), Appendix D, Article 8.6.

38 See Barrera-Hernández, et al., supra note 3. 
СвD; for instance, on when benefit-sharing arrangements might be triggered, on what counts as a benefit, and on how such matters should be decided. As such, benefit-sharing arrangements may be deployed in a variety of contexts and circumstances that are different to the approach taken under the свD. The scope and content of specific arrangements may, in those instances, be determined by requirements embedded, for instance, in national or international law, or by voluntary guidelines adopted by national or subnational governments, contracts, or corporate standards or practice. The picture is therefore fairly messy: it can be difficult to establish what benefit-sharing is taken to mean in all of the contexts in which it is used - or, indeed, whether there is any sectoral consistency.

\subsection{Arguments about Universality or Ad Hoc Approaches to Benefit-Sharing in International Law}

Accordingly, benefit-sharing is an emerging norm of international law with high-consensus support for its legal significance, seeking to protect the rights of IPLC in specifically defined contexts. There is strong authority that supports the integration of benefit-sharing across regimes in a way that resembles the application of benefit-sharing under the СвD (discussed above). Yet, on the whole, where benefit-sharing is already used in the climate regime, ${ }^{39}$ it more closely resembles human rights protection, most likely because it is more frequently used to counter the impacts of climate responses than to empower participation in for-profit activities. ${ }^{40}$ Benefit-sharing also appears on an ad hoc basis in various private or domestic instruments in relation to various climate response measures. The way these arrangements are conceptualized and formulated is mostly instance-specific.

So, returning to the questions tackled in this article and discussed in the first section: while the case for the existence of an emerging norm of benefit-sharing in international law is compelling, the answers to the subsidiary questions are less clear and are difficult to disentangle. We still need to know to what extent benefit-sharing as deployed in climate law or climate finance law resembles

39 Which includes forests: Decision 1/CP.16, Cancun Agreements, UN Doc. FCCC/CP/2010/7/ Add.1, Appendix I, para. 2. REDD+ does not expressly require benefit-sharing but it is routinely used; see Wong, et al., supra note 12 , and climate finance, as discussed below. See Savaresi and Bouwer, supra note 4.

40 Savaresi, supra note 2,15 . However, the discussions in the climate regime around the amelioration of the social and economic consequences of mitigation responses to climate change, called 'response measures', are both broader and more long-standing than benefitsharing; see Nicholas Chan, "The "New" Impacts of the Implementation of Climate Change Response Measures', 25 RECIEL 228 (2016). 
the more established formulation under the $\mathrm{CBD}$, or whether it should do so. This gives rise to further questions about whether any differences are preferable, or even necessary, and whether standardization is likely to support better results or provide assurances relating to equity and fairness.

On the one hand, strong arguments can be made for sustaining these defined universal norms, not least in order to establish coherence in the use of such arrangements, and to ensure that gains in some areas are not lost in others. ${ }^{41}$ It is valuable to extract key normative concepts from specific cross-sectorial practices in order to provide headline guidance for the development of benefit-sharing arrangements in different contexts. ${ }^{42}$ This article attempts this in the Section 4. On the other hand, it is clear that the idea of universalized norms is not universally accepted, ${ }^{43}$ and equally strong arguments can be made for flexibility and responsiveness in different areas. The reasons for this relate to the particularity of benefit-sharing arrangements and how these should be developed in each set of circumstances. The very specific and localized nature of many of these arrangements is a reason for ad hoc development, ${ }^{44}$ the rationale being to avoid the imposition of predetermined features on vulnerable people. Universalized norms could overwhelm the contribution made by the supposed benefit-recipients in the course of their own participation - for instance, by limiting the scope for them to shape their own arrangements according to their values and preferences. These considerations include the importance of the vulnerable participants' voices and priorities in framing the nature and circumstances of the arrangements. In essence, it is accepted practice that benefits should genuinely reflect net benefits to the receiving community, and that this cannot be standardized but must be developed de novo in each instance.

There is, however, a significant trend arising in the practice of benefit-sharing that would motivate the development of headline norms for these kinds of safeguards. Despite the absence of treaty recognition of benefit-sharing in the climate regime, there is widespread if varied practice on benefit-sharing on various levels, seemingly without clear articulation as to what benefit-sharing means, or consistency in minimum standards or best practice. These arrangements are unlikely to be developed entirely ad hoc. In some cases they might be

41 Elisa Morgera, 'The Need for an International Legal Concept of Fair and Equitable Benefit Sharing', 27 European Journal of International Law 353 (2016). Discussions under the CBD have fleshed out this concept: ibid., 365 f.

42 Chapman, Wilder, and Miller, supra note 12.

43 For instance, Chapman, Wilder, and Miller, supra note 12, argue for similar reasons against 'predetermined' approaches to benefit-sharing, but, despite this, recognize some core features.

Ibid. 
regulated through national legislation or formal guidance or codes. ${ }^{45}$ However, there also appears to be a proliferation of approaches to benefit-sharing in (predominantly) private instruments, where norms develop that are specific to a sectoral context or even to key actors in an industry or field. ${ }^{46}$ They include formal and informal as well as sector- or industry-specific codes of industry practice or private contracts, in various contexts. ${ }^{47}$ This could happen through corporate standard-form agreements forming the basis (or entirety) of agreements, or through more subtle processes whereby the idea, content, and process of the agreement become replicated through exchange. ${ }^{48}$ These contracts, together with any industry codes, would to some extent standardize benefit-sharing within an industry, ${ }^{49}$ which may not be done in a way that meets the aspirations of benefit-sharing. For instance, Affolder argues that the variegation of voluntary contractual arrangements used for forest conservation entrenches private authority within the broader field..$^{50}$ What is not clear is the extent to which the subjects of the benefit-sharing arrangements - the frequently vulnerable 'recipients' of benefits - are able to shape the relationships formed under these agreements in different contexts. ${ }^{51}$ If the appreciation of the vast power imbalance between the contracting parties is inherent in the

45 Savaresi and Bouwer, supra note 4, section 2(a). E.g. the South African National Environmental Management Protected Areas Act (Act 57 of 2003). For a comparative discussion of domestic legislative approaches to benefit-sharing under REDD+ in three African countries, see Jegede, supra note 3 .

46 Ibid.; and Ciaran O'Faircheallaigh, 'Community Development Agreements in the Mining Industry: An Emerging Global Phenomenon', 44 Community Development 222 (2013). On private and 'quasi-private' standards generally, see Joanne Scott, 'Private and QuasiPrivate Standards', in Lavanya Rajamani and Jacqueline Peel (eds), The Oxford Handbook of International Environmental Law (2nd edn, Oxford University Press, 2021).

47 Yinka Omorogbe, 'Resource Control and Benefit Sharing in Nigeria', in Barrera-Hernández, et al. (eds), supra note 4, sections IV-VI.

48 O'Faircheallaigh, supra note 46; Natasha Affolder, 'Looking for Law in Unusual Places: CrossBorder Diffusion of Environmental Norms', 7 Transnational Environmental Law 425 (2018), section 3 .

49 Even if setting standards is not an overt aim of these agreements, it suggests that they can constitute a form of private governance, with their use by repeat players implicitly setting industry standards. See Neil Craik, Holly Gardner, and Daniel McCarthy, 'IndigenousCorporate Private Governance and Legitimacy: Lessons Learned from Impact and Benefit Agreements', 52 Resources Policy 379 (2017). On private standards generally, see Scott, supra note 46.

50 Natasha Affolder, 'Transnational Carbon Contracting: Why Law's Invisibility Matters', in A. Claire Cutler and Thomas Dietz (eds), The Politics of Private Transnational Governance by Contract (Routledge, 2017).

$5^{1}$ Omorogbe, supra note 46. 
rationale for benefit-sharing, ${ }^{52}$ the risk of an equity deficit in negotiations due to gaps in commercial sophistication, negotiating acumen, knowledge gaps, and political leverage - fundamentally, power - must also be appreciated. ${ }^{53}$ In some circumstances, benefit-recipients have become sophisticated negotiators, and are able to negotiate favourable terms and assert their rights judiciously and enforce them judicially. ${ }^{54}$ But securing and enforcing satisfactory arrangements should not be contingent on this, and there is clear evidence that where corporate practices are developed ad hoc in circumstances of poor (or no) institutional guidance, this can give rise to substantial shortcomings in terms of both procedural and substantive legitimacy, with the result that the value of 'benefits' is dubious given the overall economic picture of the project..$^{55}$ There is also the undeniable reality that, no matter how skilled they might be in negotiation, all parties are aware that the IPLC in most cases do not have power to prevent or relocate the project.

This also creates challenges in terms of knowledge and understanding. Commercial contracts are opaque and inaccessible for 'commercial sensitivity' reasons, meaning for the most part that where they do constitute industry standards on benefit-sharing they cannot be evaluated or compared with other arrangements or international norms, or assessed for how they might support just and equitable outcomes. While confidentiality on some features can protect the interests of vulnerable benefit-recipients, ${ }^{56}$ standard confidentiality erodes transparency and the potential for cross-community learning, as well as any holistic discussion of benefits, and accordingly disadvantages other groups in negotiations. ${ }^{57} \mathrm{~A}$ standardization approach that includes requirements to introduce benefit-sharing, defined with reference to minimum international

52 Ken J. Caine and Naomi Krogman, 'Powerful or Just Plain Power-Full? A Power Analysis of Impact and Benefit Agreements in Canada's North', 23 Organization and Environment 76 (2010).

53 Ibid.; O'Faircheallaigh, supra note 46; and Paola Velasco Herrejon and Annalisa Savaresi, 'Wind Energy, Benefit-Sharing and Indigenous Peoples: Lessons from the Isthmus of Tehuantepec, Southern Mexico', 1 Oil, Gas and Energy Law Journal (2020), section 3.1.

54 Alastair Lucas, 'Participatory Rights and Strategic Litigation', in Barrera-Hernández, et al. (eds), supra note 2.

55 Craik, Gardner, and McCarthy, supra note 49; Louise Schwemmer, Rina Grant, Wendy Anneke, and Stefanie Freitag-Ronaldson, 'Toward More Effective Benefit Sharing in South African National Parks', 28 Society and Natural Resources 4 (2015).

56 The broader arguments around confidentiality in commercial contracts are complex and multi-layered, and certainly without these crucial protections projects as a whole may be jeopardized, which may be to the detriment of the benefit recipients or the projects per se. So the suggestion is not to 'do away with' confidential contracts in and of themselves, but merely that benefit arrangements can be problematic if concluded on this basis.

57 Caine and Krogman, supra note 52, 86. 
standards, and includes arrangements for ongoing dialogue, could require transparency in these arrangements. ${ }^{58}$ This could support other communities in understanding the possibilities, procedures, and gains made elsewhere, as well as ensure that rights won in other contexts are not negotiated away. Indeed, the need to regulate private actors and to ensure that benefit-sharing arrangements meet minimum standards was a significant motivator for Knox to require the formalization of a norm of benefit-sharing.

Adjacent to questions about the content of the norm in specific contexts lies the issue that while benefit-sharing has the potential to yield positive and powerful results, there are strong indications that it is at best difficult to evaluate it in terms of effectiveness; 59 at worst, it fails as a tool of engagement. The empirical evidence evaluating benefit-sharing arrangements across a variety of contexts reveals mixed results at best. ${ }^{60}$ For instance, even though the $\mathrm{CBD}$ regime provides the most detailed guidance on the implementation of benefit-sharing arrangements, benefit-sharing arrangements introduced in accordance with this guidance are not above criticism in their own context. ${ }^{61}$ Problems range from failures in engagement and participation, failures of benefit-sharing arrangements to improve the situation of recipients, and a range of unintended consequences. In some instances the arrangements reflect poor recognition of the recipients' preferences and interests, resulting in useless or unhelpful arrangements or loss of property rights or community space in exchange for their traditional knowledge. ${ }^{62}$ In others, poorly designed arrangements have caused or exacerbated community tensions, causing violent conflict. ${ }^{63}$ The diversity of circumstances in which these arrangements are employed, and the arrangements' frequent opacity (even to benefit-recipients), has meant that establishing precisely what went wrong and how to fix it has presented tremendous challenges. Of course, this also begs the question about what success in benefit-sharing arrangements might mean, despite the

$5^{8}$ See Olawuyi, supra note 14, 119f, on the benefits of transparency in carbon projects.

59 Caine and Krogman, supra note 52, 81 .

6o Louisa Parks, Benefit-Sharing in Environmental Governance (Routledge, 2019), Chapters 2 and 3 .

61 Medaglia, supra note 20.

62 Vermeylen, supra note 15; Ara Azad and Ava Azad, 'Energy Justice, Climate Justice, and Financing Innovation', in Randall Abate (ed.), Climate Justice (Environmental Law Institute, 2016); Shalanda H. Baker, 'Project Finance and Sustainable Development in the Global South', in Alam, et al. (eds), supra note 20.

63 J. S. Kemerink-Seyoum, T. M. Tadessea, W. K. Mershaa, A. E. C. Dukera, and C. De Fraiture, 'Sharing Benefits or Fueling Conflicts? The Elusive Quest for Organizational Blue-Prints in Climate Financed Forestry Projects in Ethiopia', 53 Global Environmental Change 265 (2018). 
suggestion that these may be evaluated according to how they 'continue to provide meaningful benefits to those signed on to them and enhance their ability to negotiate more effectively over time for those benefits that are perceived as fair and potentially necessary to tolerate the negative impacts of development'.64

The emblematic features of many of these relationships are deep inequality in resources, knowledge and (sometimes) savoir faire, and inherent power imbalances. A case can be made that even where benefit-sharing arrangements can afford much-needed recognition to communities, ${ }^{65}$ there is a limit to what can be achieved in terms of the distributive power of benefit-sharing arrangements, and that these very inequities may make the achievement of fair, or indeed entirely voluntary arrangements, impossible. For instance, the offered arrangements could be seen as a 'bribe' or an unsavoury inducement to marginalized people with few other options. ${ }^{66}$ This raises all sorts of questions as to whether, despite their increasing use in practice and academic interest, introducing contractual or quasi-contractual arrangements in such a context could ever be entirely voluntary, or whether they could ever support fairer outcomes than otherwise, let alone address underlying distributive issues.

This presents something of a conundrum for the development of benefit-sharing both as a concept and as a practice. It is problematic to promote as a normative 'good' a mechanism that is substantially failing as a tool of engagement in most of its current manifestations. But given the broad and increasing use of these arrangements, perhaps using best endeavours to ensure an approximation to fairness and voluntary engagement, while acknowledging that the practice of benefit-sharing will be imperfect, is the best that can be achieved in most contexts. ${ }^{67}$ It is unlikely that moral and political pressure to distribute the benefits of carbon projects will lessen in the future, and so benefit-sharing will continue to be used in the climate context.

64 O'Faircheallaigh, cited in Caine and Krogman, supra note 52, 89.

65 Parks, supra note 6o, chapter 4.

66 Noel Cass, Gordon Walker, and Patrick Devine-Wright, 'Good Neighbours, Public Relations and Bribes: The Politics and Perceptions of Community Benefit Provision in Renewable Energy Development in the UK', 12 Journal of Environmental Policy and Planning 255 (2010); and Gardar Arnason and Doris Schroeder, 'Exploring Central Philosophical Concepts in Benefit Sharing: Vulnerability, Exploitation and Undue Inducement', in Doris Schroeder and Julie Cook (eds), Benefit Sharing: From Biodiversity to Human Genetics (Springer, 2013)although the authors dispute that this is always necessarily the case.

67 Chiara Armeni, 'Participation in Environmental Decision-Making: Reflecting on Planning and Community Benefits for Major Wind Farms', 28 Journal of Environmental Law 415 (2016). See also Louisa Parks and Elisa Morgera, 'The Need for an Interdisciplinary Approach to Norm Diffusion: The Case of Fair and Equitable Benefit-Sharing', 24 RECIEL 353 (2015), 356. 
But none of the above is necessarily a definitive argument against the formalization of headline norms. It is not clear whether any of the above difficulties could be avoided if clear universal norms and minimum standards were established, and in turn whether problems could be avoided through better institutions, better enforcement, and the more sensitive application of core principles. A clear norm would at least put parties on an equal footing by preserving minimum standards or best practices in relation to benefit-sharing, in that these would be standardized through instruments informed by human rights, rather than corporate expedience. It would also make benefit-sharing arrangements more likely to be deployed in circumstances where they are required. This would not preclude the negotiation of more favourable or desirable conditions by some benefit-recipients where appropriate or possible, nor would it preclude parties from agreeing to arrangements that represent an improvement or progression beyond universalized minimum standards, yet still ensure that gains won in one area are not lost in others. An alternative view is that the arrangements are fundamentally ideologically or conceptually flawed and can never deliver equity and justice in the way envisaged, ${ }^{68}$ but (as flagged above) this is an argument less against the standardization of arrangements than against the use of benefit-sharing arrangements per se.

\subsection{Benefit-Sharing in the Climate Regime}

There are no express provisions on benefit-sharing in the climate treaties. However, it is possible to read in benefit-sharing as required by other treaty protections, in particular references to human rights, as discussed below. The absence of a conflict clause in the UNFCCC may be understood to mandate harmonious interpretations of the regimes on human rights and climate. 'As there is no intrinsic priority of one set of [regime] obligations over [an]other, when faced with implementation conflicts, obligations under the UNFCCC should be interpreted in such a way as to support, rather than conflict with, human rights.' 69

Some celebrate the inclusion of human rights as a triumph of the Paris Agreement $(\mathrm{PA}),{ }^{70}$ but the Framework Convention already 'echo[ed] concerns closely aligned with human rights obligations - from a recognition of

68 For instance, Birrell and Godden, supra note 12, critique benefit-sharing as the 'commodification of a moral imperative'.

69 Savaresi, supra note 2, 16.

70 Daniel Klein, Maria Pia Carazo, Meinhard Doelle, Jane Bulmer, Andrew Higham, and Inge Knittke (eds), The Paris Agreement on Climate Change: Analysis and Commentary (Oxford University Press, 2017), 114-17. 
the central role of the principle of equity, to [the] need to acknowledge the vulnerability of specific groups, or to references to ... public participation.71 The Cancun Agreements require respect for human rights in relation to all climate responses; ${ }^{72}$ this supported the introduction of social and environmental safeguards. ${ }^{73}$ There is also emphasis on human rights and protection of the vulnerable in the $\mathrm{PA}^{,{ }^{74}}$ both in the express inclusion of a human rights reference and through the increasing 'relevance of human rights norms' in the climate regime. ${ }^{75}$ The PA requires parties 'when taking action to address climate change, [to] respect, promote and consider their respective obligations on human rights', including the rights of indigenous peoples, local communities, and 'people in vulnerable situations', as well as in relation to the right to development. The fairly watery wording and positioning of this provision suggest that its authority and usefulness are circumscribed. ${ }^{76}$ However, some recognition (albeit weak) is afforded to principles related to human rights, particularly in relation to matters of procedure and participation and the rights of indigenous peoples. ${ }^{77}$ Article 12 of the PA emphasizes the importance of procedural rights, requiring co-operation in relation to various measures including 'public participation and public access to information, recognizing the importance of these steps with respect to enhancing actions under this Agreement. ${ }^{78}$ Thus although the PA does not expressly incorporate human rights obligations into the climate regime, the above references could be seen as asserting the importance of the protection of human rights in the face of the climate challenge. ${ }^{79}$

The 2018 Paris 'Rulebook' includes provisions on modalities, procedures, and guidelines for the operation of the PA, including mechanisms for increased transparency and accountability, as well as compliance. ${ }^{80}$ Hopes for a strongly 'rights-based' implementation package were not fulfilled, but this is consistent with its overall tone and wording of the rules, which are strongly procedural

Sébastien Duyck, 'Delivering on the Paris Promises? Review of the Paris Agreement's Implementing Guidelines from a Human Rights Perspective', 9 Climate Law 202 (2019), 204, and section 2.1.

73 Again, under REDD+. See Savaresi and Bouwer, supra note 4, section 3(a).

74 Paris Agreement, Preamble.

75 Duyck, supra note 71, 207.

76 Alan Boyle, 'Climate Change, the Paris Agreement and Human Rights', 67 International and Comparative Law Quarterly 759 (2018), 769-70.

77 Duyck, supra note 71.

78 Paris Agreement, Article 12.

79 Annalisa Savaresi and Joanne Scott, 'Implementing the Paris Agreement: Lessons from the Global Human Rights Regime', 9 Climate Law 159 (2019).

$80 \quad$ FCCC $/ \mathrm{PA} / \mathrm{CMA} / 2018 / 3 /$ Add.2 (2018). 
and without any reference to rights, justice, or equity; also the parties to the PA bear human rights obligations through international law in any event. ${ }^{81}$ Some provisions in the Rulebook could be read as supportive of the inclusion of human-rights based protections, including benefit-sharing; for example, it reiterates the recognition that the implementation of climate responses (which would include projects funded with climate finance) can have an impact, noting that 'Parties may be affected not only by climate change but also by the impacts of the measures taken in response to it'.82 This entails that climate change responses must not exacerbate existing inequalities or be contrary to existing human rights protections. The Rulebook establishes a forum on the impact of climate responses. ${ }^{83}$ The modalities and procedures of the forum include the promotion of 'action to minimize the adverse impacts and maximize the positive impacts of the implementation of response measures', ${ }^{84}$ which surely implies proactive safeguards to ensure fair distribution of the advantages and disadvantages of climate responses.

Finally, although not specific to the Rulebook, there is improved recognition among UNFCCC parties of the role of indigenous people and local communities. A Local Communities and Indigenous Peoples Platform was created at COP 23 to strengthen the knowledge, practices, and efforts of IPLC in responding to climate change. It emphasizes the sharing and strengthening of knowledge and the enhancement of engagement in the overall UNFCCC process. ${ }^{85}$ The need to engage with and seek the contribution of IPLC in the formulation and implementation of mitigation action as well as national adaptation plans, and to seek their participation in relation to adaptation planning, is expressly recognized. ${ }^{86}$ While this inclusion emphasizes the importance of the broader contribution that IPLC can make in relation to climate change, the strengthening of their status and the specific emphasis on their involvement needing to be 'in accordance with international law' reflect the importance indigenous people's rights and interests in the climate regime. This could be read as extending entitlements of benefit-sharing to climate responses.

\footnotetext{
$81 \quad$ Duyck, supra note 71.

82 Decision $7 /$ CP.24, preambular paragraphs. For background, see Chan, supra note 40.

83 Decision $7 /$ CMA.1.

84 Annex to Decision 7/CMA.1, para. 1(f).

85 Decision 2/CP.23, Local Communities and Indigenous Peoples Platform, FCCC/CP/2017/11/ Add.1 (2017), preamble and para. 6(c).

86 Decision 8/CP.24, Article 12; Decision 9/CP.24, Article 8.
} 
This section will discuss climate finance, before going on to explore how benefit-sharing arrangements have been actualized by the 'climate funds'.

\subsection{Climate Finance - What Is It?}

This first subsection seeks to confirm what climate finance is and can be used for, which is helpful for understanding what follows. Climate finance can cover the costs and risks of climate mitigation and adaptation actions, ensuring low-carbon development as well as improved resilience and adaptation measures. ${ }^{87}$ It can be used to support climate-mitigation projects, specifically the development of low-carbon and renewable energy technologies. ${ }^{88}$ It can also be used to support the implementation of mitigation policies, including incentives such as subsidies, feed-in tariffs, or tax breaks, ${ }^{89}$ the supply of technologies, or the costs of removing barriers to technology introduction. This includes institutional and regulatory barriers, behavioural and educational impediments, and problems of capacity and readiness to receive. ${ }^{90}$ Climate finance can support capacity-building and technical assistance, and is a prerequisite to full participation in the Paris Agreement, for instance in compiling NDC s and complying with the treaty's transparency processes. ${ }^{91}$

Understanding what climate finance does and how it does it also requires an understanding of the processes through which climate finance is 'delivered' through climate funds. When I refer to 'climate funds' below, I am referring to the treaty climate funds. In this article's context, they are a small group of intermediary bodies to the climate regime, established under the UNFCCC and Kyoto Protocol, and, now, the Paris Agreement. The Global Environmental Facility is an independent multilateral financial institution that provides grants to developing countries for projects related to climate change and other environmental issues such as land restoration and pollution control. It is the long-standing operating entity of the Financial Mechanism of the

87 Although adaptation measures continue to be underfunded: UNFCCC SCF, supra note 1.

88 Søren Lütken, Financial Engineering of Climate Investment in Developing Countries (Anthem Press, 2014), Chapter 1.

89 Ibid., 59-61.

9o On the barriers to technology transfer, see Kim Bouwer, 'Insights for Climate Technology Transfer from International Environmental and Human Rights Law', 23Journal of Intellectual Property Rights 7 (2018).

91 See, for instance, Paris Agreement, Article 13.14.

92 The Financial Mechanism was created under UnfCCC, Article 11, and the GEF of the UN Environment Programme and the International Bank for Reconstruction and Development 
UNFCCC, ${ }^{92}$ with two climate funds, the Special Climate Change Fund and the Least Developed Countries Fund. ${ }^{93}$ The Adaptation Fund (AF) was established under the Kyoto Protocol to finance adaptation programmes and projects in developing countries that are particularly vulnerable to the adverse effects of climate change. ${ }^{94}$ At the $2018 \mathrm{COP}$ it was included as a funding mechanism to serve the Paris Agreement. ${ }^{95}$ The Green Climate Fund was established at the $2010 \mathrm{COP}$ with the goal of channelling finance to developing countries for policies, programmes, and projects on mitigation and adaptation to climate change; ${ }^{96}$ it was subsequently operationalized at the $2014 \mathrm{COP}$.

However, these are not the only, or only public, finance institutions in climate finance. Nevertheless, the climate funds are the logical place to start an enquiry of this nature, ${ }^{97}$ not least because they operate within the climate regime and some elements in their constitutional documents recognize the need for benefit-sharing, as detailed below. Other public institutions such as development banks establish climate funds or otherwise deploy climate finance. For instance, the World Bank hosts a number of multilateral investment funds, including the Climate Investment Funds and the Clean Technology Fund. ${ }^{98}$ Private institutional investors, such as pension funds or insurance companies, which already provide a significant proportion of donor finance both domestically and internationally, may also have their own climate funding architecture..$^{99}$ The contribution of private finance and private institutions is relevant to this study insofar as they are involved in the provision of finance in conjunction with multilateral climate funds.

was restructured and entrusted with its operation under UNFCCC, Article 21.3. See Richard B. Stewart, Bryce Rudyk, and Kiri Mattes, 'Governing a Fragmented Climate Finance Regime', in Hassane Cissé, Daniel D. Bradlow, and Benedict Kingsbury (eds), The World Bank Legal Review: International Financial Institutions and Global Legal Governance (The World Bank, 2011), 38 o.

93 Decision $7 /$ CP.7, The Marrakesh Accords (FCCC/CP/2001/13/Add1).

94 Ibid., Decision 10/CP.10.

95 Decision 13/CMA.1, para. 1.

96 Decision 1/CP.16, para. 102. The GCF is also an operating entity of the Financial Mechanism under UNFCCC, Article 11.

97 My motivation for this approach is mostly practical, but this is consistent with a principled approach to climate finance as treaty finance; see Alexander Zahar, Climate Change Finance and International Law (Routledge, 2016), Chapter 1.

98 Stewart, supra note 92, 372-8.

99 Barbara Buchner, Padraig Oliver, Xueying Wang, Cameron Carswell, Chavi Meattle, and Federico Mazza, 'Global Landscape of Climate Finance 2017: Climate Investment Analysis', <https://climatepolicyinitiative.org/publication/global-landscape-of-climatefinance-2017/>. 
A modest amount of project climate finance is provided directly, in the form of grants. ${ }^{100}$ Some public bodies provide grants or subsidies to support climate actions, covering the 'incremental costs' (explained below) incurred due to low-carbon choices. Grant funding could include cash transfers or the provision of some other kind of 'free' support. This can include direct payments made or channelled through climate funds, or direct support from climate funds.

Other climate-finance instruments provide support for the risk involved in climate investments. For instance, instead of subsidizing a loan, an institution could provide a guarantee or surety against default by the loan recipient, thus maintaining finance flows despite what might otherwise be a prohibitive risk. Climate funds or private investors can also ameliorate risk to investors by supporting project-financing systems, ${ }^{101}$ or can play a leveraging or aggregation function which ameliorates risk for private investors. ${ }^{102}$ This can involve portfolio-based engagement rather than the direct funding of specific projects; for instance, by creating portfolios for investors, development banks and climate funds can make investment packages attractive by ensuring an acceptable aggregate level of risk in an investment portfolio. Through this process of facilitating risk-spreading through portfolios, development banks and climate funds can leverage private capital to ensure investment is provided for key projects. ${ }^{103}$

Climate finance is most commonly provided through a range of financial instruments that enhance investment possibilities or make financing available. In this sense, climate finance is predominantly about facilitation, rather than donation. A variety of methods or financial instruments encourage new, expanded, or continuing flows of private finance, which is then used to provide 'climate finance' to fund projects and initiatives in receiving countries. ${ }^{104}$ Where private finance is involved, public finance may be used to make the investment environment more palatable for investors. A significant portion of finance is provided in form of concessional loans, ${ }^{105}$ 'blending' finance in

100 Ibid., Table 1. This covers intrastate payments to individuals or organizations, but grant payments can be made interstate as well.

101 Baker, supra note 62.

102 Lütken, supra note 88, Chapter 5 .

103 Cassie Flynn, Blending Climate Finance Through National Climate Funds (UNDP, 2011).

104 Murray Ward, Innovative Climate Finance: Examples from the UNEP Bilateral Finance Institutions Climate Change Working Group (U NEP, 2011).

105 Susanne Olbrisch, Erik Haites, Matthew Savage, Pradeep Dadhich, and Manish Kumar Shrivastana, 'Estimates of Incremental Investment for, and Cost of, Mitigation Measures in Developing Countries', in Erik Haites (ed.), International Climate Finance (Routledge, 2013). 
circumstances where repaying the loan at market rates of interest might otherwise make the project infeasible. ${ }^{106}$ They can be blended with other financial instruments - for instance, it is a common practice in climate finance to blend climate funds' low-cost loans with commercial financing from Development Finance Institutions. ${ }^{107}$

The detail offered here highlights the complexity and sophistication of many of the arrangements, but it also sheds light on the methodological and technical complications involved in tracking flows of finance. For instance, loans need to be repaid, and this does not always result in a net flow of finance from developed to developing countries. Zhang explains:

if loans and other profit-driven financial instruments are considered to be climate finance, there will be cases where the flows of climate finance, as reported, [are] in line with the rules (i.e. it is from developed to developing countries), but in reality the net transfer is in the other direction (e.g. where developing countries have to pay back the loans with interest to developed countries). ${ }^{108}$

The lack of a formal definition of climate finance means that it is difficult to delimit the scope of climate finance and determine how it should be monitored. Exercises on monitoring, verification, and reporting of finance flows are beset with uncertain working practices, gaps and uncertainty in data, and variable accounting practices. These issues are important, not least because they determine flows and usage of climate finance, ${ }^{109}$ but they need not be addressed in this article, which examines the work of the treaty climate funds.

\subsection{Climate Finance in the Climate Regime}

Climate finance is important for making progress towards the UNFCCC objectives and the PA goals. The UNFCCC requires Annex II parties to provide 'new and additional' financial resources to support developing countries with the 'full agreed incremental costs' of meeting their obligations under the treaty. ${ }^{110}$

\footnotetext{
106 Lütken, supra note 88.

107 Flynn, supra note 103.

108 Hao Zhang, 'Implementing Provisions on Climate Finance Under the Paris Agreement', 9 Climate Law 21 (2019), 35 .

109 Romain Weikmans and J. Timmons Roberts, 'The International Climate Finance Accounting Muddle: Is There Hope on the Horizon?', 11 Climate and Development 97 (2019).

$110 \quad$ UNFCCC, Article 4.3: 'shall provide'.
} 
Elsewhere, climate finance is limited to 'this difference in cost'."11 Accordingly, theoretically, climate finance refers to the resources provided to meet the difference in cost between a traditional development pathway and 'technologically advanced, less globally harmful' development, ${ }^{112}$ although of course this distinction is not always easy to make. The provision of climate finance as an obligation is reiterated under the $\mathrm{PA}$, as one of the few obligations that is framed as an imperative. ${ }^{113}$ The PA requires 'finance flows consistent with a pathway towards low greenhouse gas emissions and climate-resilient development.'114 Notions of progression are emphasized, and the provision of finance is subject to the transparency and compliance mechanisms that seek to hold parties accountable in international climate governance. ${ }^{115}$

Climate finance was a core consideration at the $2018 \mathrm{COP}$, and the need for clarity on predictability of flows, funding criteria, additionality, and the usefulness of climate finance in capacity-building and supporting necessary transitions are reflected in the operational paragraphs of the relevant decisions. ${ }^{116}$ As explained above, the Rulebook clarifies the information that needs to be provided by parties for full transparency on climate finance, and the modalities, procedures, and guidelines that specify in detail how this information should be presented. ${ }^{117}$

The focus on equity in the Rulebook relates predominantly to burden-sharing, as for instance in the requirement that a party must justify in its NDC how its NDC 'is fair and ambitious, in the light of its national circumstances, and how it contributes towards achieving the objective of the Convention as set out in its Article 2.118 But there is very little in the Rulebook that enables or supports

Zahar, supra note 97 . He illustrates a conundrum: a program delivering only global environmental benefits but no local benefits would show no difference between total and incremental costs, because the hosting country receives no benefits. Conversely, where there are only local, but no global, environmental benefits, no incremental costs are incurred and the project has no entitlement to climate finance. Ibid., Chapter 1.

113 Paris Agreement, Article 9.1, states that 'Developed country Parties shall provide financial resources to assist developing country Parties with respect to both mitigation and adaptation in continuation of their existing obligations under the Convention'. Other parties are 'encouraged' to (continue to) provide support 'voluntarily', recognizing the contribution already made by emerging market states: ibid., Article 9.2.

114 Paris Agreement, Article 2.1(c).

115 Ibid., Articles 9.5-9.7.

116 Decision 12/CMA.1, Annex. Space and this article's purpose does not permit a full discussion of all the Rulebook provisions relating to climate finance; but see Zhang, supra note 108.

In accordance with Paris Agreement, Articles 9.5, 13.9, and 13.10, and the Paris Rulebook, Decision 12/CMA.1 and Decision 18/CMA.1. 
direct evaluation from an operational perspective of the equity and justice in the provision of climate finance, and the climate funds have no corresponding transparency provisions. ${ }^{119}$ Accordingly, as argued above, there exists a norm or emerging norm of benefit-sharing under which states have obligations in international law, although the contours of this norm are somewhat fuzzy. The climate funds themselves have adopted voluntary provisions on benefit-sharing, but as will be discussed below, their concept of benefit-sharing is quite empty, which results in incoherence. Of course, the PA does encourage transparency and accountability between parties, but that is intended to ensure trust and co-operation among them to promote continued and progressive ambition. ${ }^{120}$ In any event, it seems unlikely that the implementation mechanisms of the PA could be effectively used to monitor other states' domestic compliance with human rights, the decisions of intermediary bodies, or equity considerations, in the context of the provision and receipt of climate finance.

\subsection{Benefit-Sharing and Climate Finance}

As outlined above, benefit-sharing is not a formal obligation in the international climate regime, although it has been used extensively in mechanisms that fall under it or are associated with it. ${ }^{121}$ It is employed in climate-relevant projects in domestic and other contexts, for instance in relation to renewable energy projects. ${ }^{122}$ There is, in addition, oblique reference to climate finance or development finance in the Framework Principles, discussed in Section 2. ${ }^{123}$ $\mathrm{FP}_{13}$ requires the co-operation of states 'to establish, maintain and enforce effective international legal frameworks in order to prevent, reduce and remedy transboundary and global environmental harm that interferes with the full enjoyment of human rights'. It also requires compliance with human rights obligations in the context of international financial mechanisms. The commentary to the principle states:

International financial institutions, as well as State agencies that provide international assistance, should adopt and implement environmental and social safeguards that are consistent with human rights obligations,

Savaresi and Scott, supra note 79 .

Lavanya Rajamani, 'Ambition and Differentiation in the 2015 Paris Agreement: Interpretive Possibilities and Underlying Politics', 65 International and Comparative Law Quarterly 493 (2016), 502-5.

Most notably REDD+; see Chapman, Wilder, and Miller, supra note 10.

See Maria Lee, Chiara Armeni, Javier de Cendra, Sarah Chaytor, Simon Lock, Mark Maslin, Catherine Redgwell, and Yvonne Rydin, 'Public Participation and Climate Change Infrastructure', 23 Journal of Environmental Law 33 (2013).

Knox, supra note 23 . 
including by: (a) requiring the environmental and social assessment of every proposed project and programme; (b) providing for effective public participation; (c) providing for effective procedures to enable those who may be harmed to pursue remedies; (d) requiring legal and institutional protections against environmental and social risks; and (e) including specific protections for indigenous peoples and those in vulnerable situations. ${ }^{124}$

While this elaboration does not expressly require benefit-sharing, it emphasizes the importance of substantive and procedural safeguards in international financing. The specific reference to the protections for IP could be interpreted to include all the protections of $\mathrm{FP}_{15}$, which, as noted in Section 2, include benefit-sharing. More broadly, compliance with these requirements must be interpreted to require not only appropriate benefit-sharing arrangements, for instance environmental and social assessments, but also that these are substantively fair and equitable, for instance through public participation.

\subsection{Benefit-Sharing Obligations in the Climate Funds}

The treaty 'climate funds' - the Global Environmental Facility-operated climate funds (the Special Climate Change Fund and the Least Developed Countries Fund), the Adaptation Fund, and the Green Climate Fund - all incorporate benefit-sharing requirements in their founding documents. Each fund has also developed policies and guidance to maintain standards and avoid environmental and social risks and impacts in the implementation of their projects or policies. Those of the GEF and the AF include benefit-sharing requirements, while those of the GCF could be understood to have them. ${ }^{125}$ The GEF, as of 2019, has an environmental and social policy (ESP) that applies to the GEF Secretariat and all 'project agencies'. ${ }^{126}$ It sets out a series of minimum standards in relation to environmental and social risks and impacts in all new (and in some in-progress) projects and programs, and specifies a tiered risk-mitigation approach (or mitigation hierarchy). ${ }^{127}$ The ESP also sets

\footnotetext{
124 Ibid., para. 39 .

125 This discussion relates to the current and most recent iterations of these policies. For a discussion of benefit-sharing provisions under the earlier policies, see Savaresi, supra note 2, 17-19. GEF, 'Environmental and Social Safeguard Standards (Council Document GEF/C.55/o7/ Rev.o1)', 13 June 2019, <www.thegef.org/documents/environmental-and-social-safeguardstandards $>, 12$. Ibid., Minimum Standard (MS) 1, para. 4(c); MS 3, para. 8(b); MS 5, para. 11(a)-(j).
} 
out minimum standards for benefit-sharing for IP affected by fund activities. This is supplemented by the GEF's Principles and Guidance for engaging with Indigenous Peoples (PGIP) ${ }^{128}$ and Stakeholders. ${ }^{129}$ Stakeholders are broadly defined to include various categories of potentially affected people, including IPLC, even though the benefit-sharing provisions only relate to IP. The PGIP frames environmental and social protections broadly, linking them to human rights protection, full respect for the dignity of indigenous communities, and the importance of protecting IP from the effects of development. ${ }^{130}$ The PGIP also links benefit-sharing to respect for the traditional knowledge, innovations, and practices of IP, recognizing that traditional knowledge serves as a source of information in the utilization of genetic resources, ${ }^{131}$ and 'recognising and respecting' the existing guidance on traditional knowledge and sharing of traditional resources. ${ }^{132}$ It establishes a series of 'minimum standards' in relation to the procedural safeguards, which while addressing environmental justice more generally, are components of, and necessary for, properly implementing and administering benefit-sharing arrangements. ${ }^{133}$ This of course includes participation, which in environmental decision-making is a substantive as well as procedural right. ${ }^{134}$ This is explored further in Section 4, but, for now, the concept and processes of participation are both necessary to secure other rights and important because of their capacity to inform other, substantive elements, such as consent, and the ongoing need for dialogue and recognition.

The AF's revised ESP aims to bring its practices in line with the social and environmental safeguards used by 'other leading financing institutions active in environment and development financing', the domestic laws of donor and recipient countries, and the existing policies and management systems of

128 GEF, 'Principles and Guidelines for Engagement with Indigenous Peoples (Council Document GEF/C.42/Inf.o3/Rev.1)', 21 October 2012, <www.thegef.org/documents/ indigenous-peoples $>$.

129 GEF, 'Guidelines on the Implementation of the Policy on Stakeholder Engagement (Council Document GEF/C.55/Inf.o8)', 21 November 2018, <www.thegef.org/councilmeeting-documents/guidelines-implementation-policy-stakeholder-engagement>, Definitions.

130 See e.g. GEF, supra note 128 , para. $30(a)$.

131 Ibid., para. 4o(d).

132 Ibid., para. 4O(e), 'including ... the Akwe: Kon guidelines, the Bonn Guidelines and the Nagoya Protocol [mentioned in the previous and subsequent sections of this paragraph, and encouraging] the use of the guidance contained in these documents in GEF-financed projects, as appropriate'.

133 GEF, supra note 127, 16-18.

134 Olawuyi, supra note $14,120 f$. 
many of their implementing entities. ${ }^{135}$ Although not particularly detailed, the AF's approach to benefit-sharing is the most progressive and best-developed. It establishes a risk-based screening for the social and environmental risks of proposed initiatives that could be avoided, minimized, or mitigated by the AF or its implementing entities. ${ }^{136}$ It requires that projects and programmes it supports 'shall provide fair and equitable access to benefits in a manner that is inclusive and does not impede access to basic health services, clean water and sanitation, energy, education, housing, safe and decent working conditions, and land rights, [and] should not exacerbate existing inequities, particularly with respect to marginalized or vulnerable groups', ${ }^{137}$ broadly framed. ${ }^{138}$ The implementation guidelines focus on equity and fairness, specifying that 'project/programme benefits' must be subject to a fair process and be fairly and impartially accessible. ${ }^{139}$

In contrast, the AF's guidance relating to IP does not mention benefit-sharing (and, given the ESP, does not need to), requiring projects and programmes to be consistent with international protection of $\mathrm{IP}^{140}$ and emphasizing the importance of free, prior, and informed consent (FPIC) throughout. ${ }^{141}$ Programmes and policies are also required to respect and promote international human rights, ${ }^{142}$ which are to form 'an explicit part of consultations with stakeholders during the identification and formulation of the project/programme. ${ }^{143}$ The

135 AF, 'Environmental and Social Policy (Amended in March 2016, Approved in November 2013)', March 2016, <www.adaptation-fund.org/document/environmental-and-socialpolicy-approved-in-november-2013/>, paras 2, 4, 6 .

136 Ibid., section 'D. Environmental and Social Policy Delivery Process'.

137 Ibid., subsection 'B. Environmental and Social Principles', '13. Access and Equity'. In the AF, 'Guidance Document for Implementing Entities on Compliance with the Adaptation Fund Environmental and Social Policy', <www.adaptation-fund.org/document/guidancedocument-implementing-entities-compliance-adaptation-fund-environmental-socialpolicy/>, 6, it is acknowledged that this principle might not always apply.

${ }_{13} 8$ Ibid, subsection 'B. Environmental and Social Principles', '14. Marginalized and Vulnerable Groups'. 'Projects/programmes supported by the Fund shall avoid imposing any disproportionate adverse impacts on marginalized and vulnerable groups including children, women and girls, the elderly, indigenous people, tribal groups, displaced people, refugees, people living with disabilities, and people living with HIV/AIDs. In screening any proposed project/programme, the implementing entities shall assess and consider particular impacts on marginalized and vulnerable groups.'

139 AF, supra note $137,6$.

140 However, the host country's ratification status of ILO Convention 169 may be considered: ibid., 13 .

141 Ibid., 11-12.

142 AF, supra note 135, subsection 'B. Environmental and Social Principles', '15. Human Rights'.

143 AF, supra note 137,8 . 
guidance states that compliance with the UDHR will be monitored, even when the host country is not a signatory to other core human rights treaties. ${ }^{144} \mathrm{In}$ contrast, it has fairly sparse procedural protections. It requires early identification of stakeholders and open public consultation; ${ }^{145}$ it establishes accountability mechanisms, which include a monitoring and reporting process; ${ }^{146}$ and it establishes a grievance mechanism. ${ }^{147}$

The GCF's revised policy for social and environmental safeguards seeks to 'effectively and equitably manage environmental and social risks and impacts, and improve outcomes of all GCF-financed activities', ${ }^{148}$ by 'integrating' sustainability into fund activities. ${ }^{149}$ The policy applies to all fund activities and financial instruments, ${ }^{150}$ and states a commitment to avoid or mitigate 'adverse impacts to people or environment', '151 'enhance equitable access to development benefits', 152 give 'due consideration to vulnerable and marginalised populations, groups, and individuals, local communities, indigenous peoples, and other marginalized groups of people and individuals that are affected or potentially affected by GCF-financed activities, ${ }^{\prime}{ }^{153}$ and be consistent with international human rights standards. ${ }^{154}$

The GCF policy speaks to the need for both common standards and particularity. It speaks to consistency and alignment with 'international best practices and applicable standards', 155 as well as with other safeguards established in the climate regime. ${ }^{156}$ It also requires harmonization between its own decisions and practices to ensure 'a common approach.'157 Like the GEF, it establishes a tiered approach to risk based on 'mitigation

\footnotetext{
144 Ibid., 9 .

145 AF, supra note 135, subsection 'D. Environmental and Social Policy Delivery Process', '33. Public Disclosure and Consultation'.

146 Ibid., subsection 'D. Environmental and Social Policy Delivery Process', '32. Monitoring, Reporting, and Evaluation'.

147 A brief discussion may be found in AF, supra note 137, 21.

148 GCF, Environmental and Social Policy (Board Decision B.19/10), 2018, <www.greenclimate. fund/documents/environmental-social-policy>, para. 3 .

149 Ibid., para. 8(a).

$150 \quad$ Ibid., para. 5; including jointly implemented projects: see para. 6.

151 Ibid., para. 3(a).

152 Ibid., para. $3(\mathrm{~b})$.

153 Ibid., para. 3(c).

154 Ibid., para. 8(q).

155 Ibid., para. 8(i).

156 Specifically REDD+, ibid., para. 8(n).

157 Ibid., para. 8(l). 'GCF will promote the harmonized application of environmental and social safeguards to reduce multiple and overlapping requirements for activities through the development of common approach that considers the requirements of other
} 
hierarchy', ${ }^{158}$ recognizing 'a wide range of entities, which can differ according to the scope and nature of the activities of the entities, and their capacity to manage environmental and social risks and impacts. ${ }^{\prime}{ }^{9}$ The provisions that could be read to require benefit-sharing are included in the principle relating to the treatment of IP:

All GCF-financed activities will avoid adverse impacts on indigenous peoples, and when avoidance is not possible, will minimize, mitigate and/or compensate appropriately and equitably for such impacts, in a consistent way and improve outcomes over time; promote benefits and opportunities; and respect and preserve indigenous culture, including the indigenous peoples' rights to lands, territories, resources, knowledge systems, and traditional livelihoods and practices. All GCF-financed activities will support the full and effective participation of indigenous peoples and recognize their contribution to fulfilling the GCF mandate throughout the entire life cycle of the activities. ${ }^{160}$

While this passage does not specifically require benefit-sharing, it can be read to do so. As will be explored more fully in the next section, many of the provisions of the GCF policy require the same things as benefit-sharing arrangements that are consistent with international standards, as well as 'free, prior and informed consent' and ongoing engagement throughout the life of the project. ${ }^{161}$ The quoted passage speaks to the need for 'full and effective' participation and for distinguishing between benefits and compensation (the rectification of harm or loss of rights).

More specific provision is made for the procedural aspects of environmental and social assessment. The GCF assumes responsibility for the full disclosure of information, including that related to the social and environmental safeguards. ${ }^{162}$ It requires that 'stakeholders' are consulted in matters in which they are affected, ${ }^{163}$ with additional requirements in relation to IP, 'during the

co-financing institutions while providing the highest level of environmental and social protection required among the parties, with at least the level of protection by GCF being required.'

158 Ibid., para. 8(f).

159 Ibid., para. 8(d).

16o Ibid., para. 8(p).

161 Also in ibid., para. 12(b).

162 Ibid., para. 12(a) and 61-6.

163 Ibid., paras 12(b), 18, and 67-72. 
design and implementation of the activities'164 and the formulation of environmental and social management plans. ${ }^{165}$ Extensive provision is made for monitoring and reporting. ${ }^{166}$ The ESP also establishes a grievance procedure and Independent Redress Mechanism (IRM) ${ }^{167}$ and requires that accredited entities have complementary procedures and facilitate access to the IRM. ${ }^{168}$ The IRM aims to provide redress in cases of adverse impacts brought about 'through the failure of the project or programme funded by the Fund to implement the Fund's operational policies and procedures, including environmental and social safeguards.'169

From the above, it is hard to derive a clear picture of what benefit-sharing is in the climate funds, to whom it should apply, and in what circumstances. (I will return to this point in Section 4.1.) Procedurally, all the EsP s include provisions for the governance and oversight of social and environmental safeguards, including early stakeholder identification, ongoing participation, and free, prior, and informed consent, all of which are found in the procedural elements of benefit-sharing arrangements. However, they are framed slightly differently, and only one ESP (the GCF's) includes an accountability mechanism. But perhaps more importantly there is little consistency on the substantive aspects of benefit-sharing. For instance, the GCF and AF both require consistency with international human rights standards, but, as outlined earlier, benefit-sharing in human rights law is conceptually quite empty. This lack of clarity is reflected in how these arrangements are interpreted by the funds. For instance, an empirical analysis of AF Board decisions found no obvious coherence in the approaches taken to vulnerability and benefit (i.e. project benefit) in decisions of the AF Board. ${ }^{170}$ This would suggest that there is little consistency on what counts as a benefit in the variety of financing situations where benefit-sharing might arise. If there is no coherence within the AF, it is unlikely that it exists across funding entities, or in other kinds of climate-related benefit-sharing, or in international norms in general.

Also, despite the ambitious inclusivity of most of the policies, specific provision is usually only made for IP, which is of course necessary, but

\footnotetext{
164 Ibid., para. 12(b).

165 Ibid., para. 47.

166 Ibid., para. 56-6o.

167 Ibid., para. $73^{-8 .}$

168 Ibid., para. 12.

169 Decision B.o6/og, Annex V, 'Terms of Reference of the Independent Redress Mechanism'.

170 Elise Remling and Åsa Persson, 'Who Is Adaptation for? Vulnerability and Adaptation Benefits in Proposals Approved by the UnfCcC Adaptation Fund', 7 Climate and Development 16 (2015).
} 
falls short of the conceptualization of benefit-sharing in international law, which requires protection to extend to local communities. The policies also fall short of what seems to be usual practice in climate-related project benefit-sharing, namely that communities local to, or affected by, a project are considered for benefit-sharing in some circumstances, even where they are not considered a traditional local community in the sense of the FP. The AF acknowledges this implicitly, by including benefit-sharing as a general obligation that is not specific to IP. But again, in both the AF and GCF there is no real guidance as to the circumstances in which benefit-sharing is 'triggered'. The policies seem to contemplate that they would be determined with early assessment, but do not specify what should be considered in the assessment or how it should be conducted. This makes it difficult to imagine the accrediting entity identifying all opportunities and stakeholders in potential benefit-sharing arrangements. Conversely, the GEF makes provision for benefit-sharing when projects are commercialized, but this is too narrow a framing compared to international standards, does not take sufficient account of the differences between the kinds of activities that arise in biodiversity protection and climate change (given the broad remit of the GEF), and does not take account of the overlaps or disjunctions between climate benefits and community benefits, as will be explored in the next section.

In addition to the question of whether there is consistency and coherence in the way benefit-sharing arrangements are introduced, there is the question of whether benefit-sharing proposals are considered and then introduced in the circumstances in which they 'should' be. A comprehensive review of funding proposals to the AF revealed that very few applications addressed the distribution of benefits amongst beneficiaries. ${ }^{171}$ A scoping review of GCF documents suggests that benefit-distribution arrangements are not being proposed or sought in the vast majority of funding applications. The documents show that the GCF approved eleven new projects in 2017, and that the GCF Board took a number of key policy decisions to further strengthen the operations of the Fund and its support for high-quality climate finance initiatives. ${ }^{172}$ Very few project applications from 2017-2019 sought approval for benefit-sharing arrangements, whether in their project requests or ESP reports. Benefitsharing is not necessary or appropriate in all circumstances, so the fact that

171 Ibid., 28 .

172 See <www.greenclimate.fund/documents/20182/38417/release_GCF_2017_B18.pdf/>. This review was conducted as part of the research for this article. I am grateful to Alphaeus Ngonga for his research assistance. 
benefit-sharing is not always mentioned is not indicative of anything necessarily having gone wrong in GCF decision-making. But as mentioned above, there are no clearly defined triggers for benefit-sharing in climate finance, either in the funds' guidance documents or anywhere else. As such, a determination of whether benefit-sharing arrangements are appropriate and needed is entirely discretionary and left to the accredited entity formulating the proposal. Thus, despite the references to international standards, it is difficult to see how decisions on benefit-sharing could be consistent with them in the absence of more carefully formulated guidance.

From the previous sections it emerged that benefit-sharing as a concept and practice in climate finance requires further thought. This last section deals with important or undertheorized areas in benefit-sharing in climate finance. Its purpose is not to construct a norm but to suggest key areas where the development of a norm or principles could occur. International norms and standards on benefit-sharing need to be considered and respected, but this must be done with an eye to existing practices in climate law and climate finance, and the particular nature and circumstances of the arrangements that develop in this context.

Accordingly, in this section I first refer back to the earlier discussion on the diversity of possible 'climate finance' projects and funding arrangements, which, when combined with the demanding particularities and context-specificity of benefit-sharing, can become messy. Next I look at some overarching issues relating to participation, community involvement, and representation, emphasizing their procedural necessity and substantive importance. Finally, I return to the substantive question of what benefits might mean in climate finance.

\subsection{Benefit-Sharing in Climate Finance is Heterogeneous}

Earlier in this article I summarized the many functions and delivery methods of climate finance, highlighting the inherent heterogeneity in the field meaning differences in laws and practice, the likely benefits that might arise, the involvement of the stakeholders, and the way ongoing relationships are managed - a fact that makes the prescription of a universalized model of benefit-sharing difficult. For instance, small-scale renewable energy projects frequently employ benefit-sharing arrangements that are subject to domestic laws or policy guidelines but also to the choices and practices of particular 
sub-industries or individual developers. ${ }^{173}$ This might be very different to, say, projects that aim to increase crop resilience in small-scale agriculture, which take place in an increasingly complex legal landscape of conflicting rights and policies. ${ }^{174}$ Different still might be international exchanges that seek to stimulate innovation and support capacity-building through longterm technology-development initiatives. ${ }^{175}$ All such projects could be, and are, funded by climate finance, and could potentially be subject to benefit-sharing arrangements; ${ }^{176}$ however, this raises questions about how 'benefits' would be conceptualized in the context of such multifarious projects. ${ }^{177}$

To some extent the defining character of climate finance projects is the provision of finance; yet, as described above, the instruments and modalities of climate finance vary enormously, and finance provided through the funds varies between projects, with use being made of grants, subsidies, loans, or various forms of public-private 'blended' finance. This raises a question: Why consider climate finance at all, if approaches to benefit-sharing could be determined by the substantive regimes within which climate finance is delivered? The problem with this is that it would mean accepting significant diversity in arrangements between projects supported by the same fund, which challenges basic concepts of equity and fairness. At the very least, the adoption of clear minimum standards would promote consistency with international obligations created elsewhere, and would not prevent the adoption of distinct, more specific, or better protection, if this is required by ad hoc practice, an alternative international regime, or indeed the benefit-recipients themselves.

\subsection{Starting Early with Assessment}

The ESP $s$ and associated policies of all funds underline the importance of early assessment. All climate funds prescribe review of impacts or possible risks before approval is granted, and these procedural requirements can probably be generalized across project types. Much like EIA, these environmental and social-risk assessments are a procedural requirement in environmental law, yet

173 Annalisa Savaresi, 'The Rise of Community Energy from Grassroots to Mainstream: The Role of Law and Policy', 31 Journal of Environmental Law 487 (2019).

174 Outlined in Elsa Tsioumani, 'Beyond Access and Benefit-Sharing: Lessons from the Law and Governance of Agricultural Biodiversity', 21 The Journal of World Intellectual Property 106 (2018).

175 Bouwer, supra note 9o; and David Ockwell and Rob Byrne, 'Improving Technology Transfer through National Systems of Innovation: Climate Relevant Innovation-System Builders (CRIB s)', 16 Climate Policy 836 (2016).

176 Savaresi and Bouwer, supra note 3 , section 3 (b).

177 But see, for instance, Bouwer, supra note 9o, section 6. 
can also be seen as an 'entryway into deeper, substantive legal understandings of public participation ... and wider concepts of rights and obligations in any legal system.' ${ }^{\prime 78}$ They are relevant to, but go beyond, considerations about benefit-sharing in projects. They identify project impacts and likely risks, and determine how these might be mitigated or controlled, or be subject to compensation or other forms of reparative payments. As explored further below, the line between compensation and benefit-sharing is not always clear, and international standards require that these should be assessed according to distinct processes. The assessment stage is the time at which these distinctions should be made. But an assessment also makes (or should make) an early determination about who the stakeholders are in a project.

Special Rapporteur Knox has stipulated that wherever environmental and social assessment is done, it should be done as early as possible, ${ }^{179}$ and, in relation to IPLC, it should be done in accordance with their own customs and traditions, as well as in accordance with the Guidelines established under the СвD. ${ }^{180}$ The Akwé: Kon Guidelines provide detailed and far-reaching requirements for social, environmental, and cultural impact assessments to be conducted in circumstances where the rights or interests of IP are potentially affected. ${ }^{181}$ The Guidelines cover the conduct of meetings, including establishing mechanisms for the ongoing engagement of communities and the conduct and recording of meetings. ${ }^{182}$ They provide for indigenous communities' involvement with the financial aspects of the project, including auditing and project oversight, ${ }^{183}$ thereby ensuring transparency of the financial investment and gains made in the project. They require states to provide support (legal, technical, financial, etc.) to IP to assist their engagement in these processes. They also require the establishment of a review and appeal process. ${ }^{184}$ References to these requirements are reflected, albeit inconsistently, in the funds' ESP s, which are certainly 'front-loaded' in terms of processes of risk assessment and identification of key stakeholders.

178 Natasha Affolder, 'Contagious Environmental Lawmaking', 31 Journal of Environmental Law 187 (2019), 19o; see also Knox, supra note 23, para. 25.

179 Knox, supra note 23, para. 20.

180 Ibid., paras 43 and 50. This approach was endorsed by the Inter-American Court of Human Rights in relation to indigenous people's rights in relation to extractive activities taking place on their land; see discussion in Morgera, supra note 34.

181 CBD Dec VII.16 UN Doc UneP/CBD/Cop/DEC/ViI/16 Annex F, Section IV.

182 Ibid., paras $14-17$.

183 Ibid., para. 18.

184 Ibid., para. 23. 
This early procedural process is key to the 'predetermination' of the agenda, and gets to frame the boundaries of risk and impact assessments, but also determines whether benefit-sharing arrangements are 'triggered' or indicated at the project-proposal stage. ${ }^{185}$ If the initial assessment works well, it sets the stage for the future relationship, for what could be a decades-long project, and to some extent shapes all the criteria discussed below - how the participatory processes function, who the beneficiaries are, how project benefits are understood, etc.

This having been said, the issues underlying these assessments can be seen as a subcategory of benefit-sharing, both as a procedural entry into proper arrangements and as a synecdoche for the tensions between particularity and universality that were discussed earlier in the article. As noted, EIA is an existing or emerging norm in international environmental law, yet a transnational review of the effectiveness of EIA reveals mixed results. ${ }^{186}$ If ESP s can be seen as a category of EIA, then they need to be approached with this in mind. It is not clear that EIA works in all contexts; for instance, where national laws or standards do not support robust evaluations or measures of risk, or where failures in implementation come about due to subversive interests or contrary incentives. ${ }^{187}$ This is particularly problematic for the current study, as most of the studies reflecting shortcomings come from Global South countries that would (or should) be the targeted recipients of climate finance. ${ }^{188}$ Yet it is difficult to imagine an alternative - simply not bothering with assessment processes is certainly not a solution. It is difficult to know how to tackle the complex reasons why EIA processes frequently fall short in the Global South context.

\subsection{The Importance of Participation}

The right to participation in environmental decision-making is a substantive as well as procedural right. ${ }^{189}$ The concept and processes of participation in environmental law have been well developed in the academic literature. ${ }^{190}$ Participation is considered necessary to secure the public accountability and legitimacy of any environmental project or programme. The Framework Principles, discussed above, emphasize the importance of public participation,

\footnotetext{
185 Caine and Krogman, supra note 52, 82.

186 Affolder, supra note 178.

187 Ibid., section 2.

188 Ibid., and sources cited therein.

189 Olawuyi, supra note 14, 12 of.

190 Lee, et al., supra note 122.
} 
which must be open to everyone, occur early in any process or project, and be carried out with full and complete information as to the intended project, possible decisions, and rights of the parties in that context. ${ }^{191}$

Benefit-sharing is inherently linked to participation because the former requires the ongoing balancing of rights and interests in a project. The importance of participation in benefit-sharing in the climate regime is implicitly acknowledged in the Cancun safeguards, which seek to avoid negative outcomes or results from the implementation of climate projects in forests, calling for 'full and effective participation'. ${ }^{192}$ A lack of participation or loss of access to salient information about the design and process of carbon projects has been identified as a severe shortcoming. ${ }^{193}$

In essence this requirement informs all other aspects of benefit-sharing arrangements, in that participatory processes determine the quality of the relationships that underlie established arrangements. Participation plays a role in shaping the engagement and external face of communities, as the engagement and dialogue within communities governs the internal legitimacy of community protocols and embodies the communities' approach to the project and their engagement with it. ${ }^{194}$ These are of crucial importance, for in order for the community to 'participate' in any benefit-sharing arrangements, the representatives must fulfil their role legitimately. But participation, or elements of what defines an adequate participatory processes, also underpin and inform other essential aspects of benefit-sharing. Participatory processes determine the quality and effectiveness of channels of communication between project partners (which could include any range of actors, such as climate funds, project developers, or local or national governments) and the benefit recipients, and are relevant at all stages of the project; at initiation, identification of stakeholders, risk assessment, project management, and (if relevant) accountability and redress processes. As discussed above, all climate-fund ESP s and associated documents require processes that are either constitutive of, or depend on, participation for their proper actualization.

This raises all sorts of questions as to whether benefit-sharing arrangements can create the basis for the ongoing relationships required for substantive participation in projects funded by climate finance, and indeed whether benefit 'recipients' could have adequate participatory power through existing structures to enforce and maintain benefit-sharing arrangements. Where

\footnotetext{
191 Knox, supra note 23, Principle 15 and commentary.

192 Decision 1/CP.16, The Cancun Agreements, Appendix 1.1(d).

193 Olawuyi, supra note 14, 111f.

194 Parks and Morgera, supra note 67, 340.
} 
participatory processes are examined in other contexts, and where engagement in participation is done without proper reflection and engagement, the outcomes tend to be less than constructive: reinforcing existing power imbalances ${ }^{195}$ or alienating stakeholders from the initiatives in which, or for which, their consent (or involvement) is sought ${ }^{196}$ or frustrating all parties due to the perceived futility of engaging in 'hollow' bureaucratic exercises with little real scope for consensus or dialogue. ${ }^{197}$ These ongoing processes should include a 'deliberative, consensus-based public dialogue aimed at reaching better-quality decisions through the value of individual rationalities'. 198 This needs to be more than participation with the mere aim of securing consent or 'public acceptance' - a process in which discussion aims only to secure acceptance or compliance. ${ }^{199}$

\subsection{Voice and Recognition}

Closely associated with these substantive concepts of participation is the concept of participants' voice and recognition. A sense of inclusion accrues by virtue of a recognition of preference in relation to monetary or other benefits in all benefit-sharing arrangements. Recognition is a subject but also a precondition for other forms of justice, ${ }^{200}$ and indeed social recognition is included as a non-monetary benefit in the 'menu' of benefits annexed to the Nagoya Protocol. ${ }^{201}$ The recipients' voice and priorities are important when it comes to how the benefits are framed, which further underlines the importance of participation. As Schlosberg explains:

If you are not recognized you do not participate; if you do not participate you are not recognized. In this respect justice must focus on the political

195 Maria Lee and Carolyn Abbot, 'The Usual Suspects? Public Participation Under the Aarhus Convention', 66 The Modern Law Review 80 (2003).

196 Margherita Pieraccini, 'Rethinking Participation in Environmental Decision-Making: Epistemologies of Marine Conservation in South-East England', 27 Journal of Environmental Law 45 (2015).

197 Maria Lee, et al., supra note 122. See also Lucy Natarajan, Yvonne Rydin, Simon Lock, and Maria Lee, 'Navigating the Participatory Processes of Renewable Energy Infrastructure Regulation: A “Local Participant Perspective" on the NsIP s Regime in England and Wales', 114 Energy Policy 201 (2018).

198 Armeni, supra note 67,437 .

199 Ibid.

200 Saskia Vermeylen and Gordon Walker, 'Environmental Justice, Values and Biological Diversity: The San and the Hoodia Benefit Sharing Agreement', in JoAnn Carmin and Julian Agyeman (eds), Environmental Inequalities Beyond Borders: Local Perspectives on Global Injustices (MIT Press, 2011), 108; Parks, supra note 6o, Chapter 4.

Nagoya Protocol, Annex 2(p). 
process as a way to address both the inequitable distribution of social goods and the conditions undermining social recognition. ${ }^{202}$

This raises all sorts of questions about perspective, worldview, and knowledge when it comes to the determination of benefits accruing from climate finance projects and the framework through which these should be delivered. They need to be designed to suit recipients' particular needs and priorities. This is not an argument against systematization and universalization of these norms, and it certainly raises no conflict with the requirement that full information about all aspects of the proposed project and associated rights be provided. The provision of full information and the preservation of minimum standards and best practices should preserve a space for recipient voices; this is not the same as the imposition of pre-determined benefits packages.

\subsection{Community/Benefit Recipients}

Benefit-sharing in climate finance raises new questions about actors and participants, and in particular about who the benefit recipients are. First, benefit-sharing as a norm in international human rights law and biodiversity law originated as a means to protect the rights and interests of IP in contexts where their traditional knowledge or natural resources were to be used or exploited by corporate or other interests. Its current status as an emerging norm in international human rights law and environmental law asserts the rights of IPLC. At the very least, therefore, there should be an obligation to consider benefit-sharing arrangements with indigenous people and local communities where a project is funded by climate finance; at present this is not reflected by all of the environmental and social safeguards. There is a reason why hardfought safeguards for IPLC are enshrined in international human rights law and biodiversity law, and what follows should not be taken to detract for that, or in any way dilute the significance of what is required in terms of protecting IPLC interests. But prescribed categories of benefit-sharing recipients extend beyond this under international law. For instance, rights of 'farmers' to benefit-sharing are protected in agricultural regimes, ${ }^{203}$ or those of small-scale fishermen in certain marine regimes. ${ }^{204}$

Moreover, in many instances benefit-sharing arrangements under climate finance have more in common with benefit-sharing under human rights law, or energy projects, as they relate to various aspects of the climate response.

\footnotetext{
202 Cited in Vermeylen and Walker, supra note 200, 108.

203 Tsioumani, supra note 174.

204 Morgera, supra note 41, 378.
} 
So, renewable energy projects, seed resilience schemes, technology innovation centres, etc., all are likely to have different effects and implications for a community, or generate benefits in circumstances where distributive justice requires that they be fairly allocated amongst involved or affected participants. This presents complex challenges in determining the scope or character of specific communities, which could be largely inchoate in relation to who is included, who is excluded, who makes the decisions about inclusion, and how these communities are governed internally - all of which are important issues in benefit-sharing practice. ${ }^{205}$ Strong governance and accountability processes within communities can support a fairer internal distribution of benefits and prevent or mitigate against social disruption and other conflicts. ${ }^{206}$ But these processes can also be intensely divisive, creating or exacerbating power hierarchies, and hence internal distributive patterns within communities. ${ }^{207}$

The extensive literature on communities in social and political science problematizes these questions in complex and dynamic conceptions of community. ${ }^{208}$ For benefit-sharing purposes, conceptions of community anchored around place or shared interests are most useful in determining how to make sense of 'community' as determinative of rights or interests of a group. ${ }^{209}$ For instance, del Guayo proposes a concept of 'energy community' as including those who are spatially or legally constructed, or who are formed through the shared experience of adverse impacts of an energy project. ${ }^{210}$ The complex and contested notion of 'community' can seem like an ungovernable complexity, or an opportunity for a free-for-all in seeking undeserved benefits. But legal or regulatory frameworks on other levels of governance have sought to define

205 Barrera-Hernandez, et al., supra note 3, 9, and the volume generally. For instance: 'Community involves not only shared identity, but to varying degrees, also the sharing of resources. Distributional justice issues around "sharing" may resonate within a community based in bonds of trust and personal relationships but may also imply not sharing with outsiders. Thus, the processes of definition of a community and the exercise of power within a community may play out in the distribution or sharing of costs and benefits. Indeed, many energy and resource projects may prove to be highly divisive for "local" communities and may lead to group conflicts.' Also O'Faircheallaigh, supra note 46, $223-7$ and $232-3$.

206 Rachel Wynberg and Maria Hauck, 'People, Power, and the Coast: A Conceptual Framework for Understanding and Implementing Benefit Sharing', 19 Ecology and Society 27 (2014).

207 Barry Barton and Michael Goldsmith, 'Community and Sharing', in Barrera-Hernández, et al. (eds) supra note 3 .

208 Ibid.

209 Savaresi, supra note 173, 9.

210 Inigo del Guayo, 'Regional and Local Energy Communities: A European Union Perspective on Community Benefits', in Barrera-Hernández, et al. (eds), supra note 3. 
the boundaries of, or conditions for, community claims. ${ }^{211}$ For instance, the EU Renewables Directive establishes criteria for energy communities based on voluntariness, autonomy, spatial proximity to the project in question, and membership or shareholding in a relevant governing body. ${ }^{212}$

\subsection{Benefits}

The final, substantive issue concerns what might be considered a 'benefit' in the broad and heterogeneous context of climate finance. Here I draw on some useful principles from other regimes that could help to frame what a benefit is, before asking some difficult questions about the relationship between benefits and financing instruments. Climate issues make determinations of 'benefit' particularly complicated, as do financing and monetary issues.

As discussed above, climate finance is the 'additional' financing provided to support the transition to a low-carbon society. In some instances this 'additional' amount reflects what is required to make a low-carbon project viable. So in many instances the 'benefit' generated with climate finance is progress towards the amelioration of climate change, whether in terms of projected carbon reductions or increased resilience. It is important to recognize that the benefits calculable from climate finance may not align perfectly with climate goals. ${ }^{213}$ Where projects generate profits, a financial benefit is more easily identifiable. $^{214}$ If the only project benefits are carbon reductions, there is still a potential for reallocation, as employed in other areas of the climate regime. This is not unproblematic, for where this has been done it has also been subjected to significant criticism, not least due to its disastrous implications for 'benefit recipients.'215

An empirical analysis of project funding through the AF has revealed very low inclusion of 'distributable benefits' in project applications. ${ }^{216}$ This could reflect a failure or refusal to take benefit-sharing seriously; but it could also be indicative of an overlap between development or resilience benefits and

\footnotetext{
211 Barton and Goldsmith, supra note 207, 39f.

212 Savaresi, supra note 173, 9.

213 See, e.g., Ara Azad and Ava Azad, 'Energy Justice, Climate Justice, and Financing Innovation', in Randall Abate (ed.), Climate Justice (Environmental Law Institute, 2016), where the recipients did not want the 'green' hydropower as a benefit, as it caused other problems.

214 See, e.g., Savaresi supra note 2, 10, on the heated debate concerning the reporting of noncarbon benefits under REDD+.

215 See, e.g., Leo Peskett, Benefit Sharing in REDD+: Exploring the Implications for Poor and Vulnerable People (World Bank, 2011).

216 Remling and Persson, supra note 170, 9.
} 
adaptation funding. Take the example of seed resilience in an agricultural project: if the entire purpose of the project is to support farmers' capacity in changing environmental conditions, there may be no benefits beyond this improved capacity. If such projects produce diffuse gains across local communities, ${ }^{217}$ it makes little sense to seek to distribute benefits if the project aims to benefit the community. From a commercial perspective, such projects reflect an absence: an increased resilience to climate change that benefits a local community in terms of what they experience less of - viz. seed loss. Still, as discussed below, there is potential for benefit-sharing in such arrangements perhaps in shared licensing or intellectual property rights, capacity-building, or other educational opportunities. These are all recognized as benefits under different regimes in international law.

Apart from particular issues to do with climate responses or climate finance, there are some well-established principles that continue to be used in biodiversity law, ${ }^{218}$ or the law on energy or natural-resource extraction, ${ }^{219}$ which may be compatible with benefits arising in a different context. At a minimum, this should include a broad concept of 'benefits' which can be both monetary and non-monetary. For instance, a narrow conception of benefit may exclude indirect or non-monetary benefits (or, as discussed below, conflate these with other payments or entitlements), particularly if formalized approaches devalue non-monetary benefits. ${ }^{220}$ The Nagoya Protocol has a 'menu' of monetary and non-monetary benefits, mostly compatible with climate finance projects; they include various kinds of financial payments, such as license fees, as well as payments to trust funds or taking the form of salaries; and the menu lists non-monetary benefits, including a range of technology-access solutions and capacity building, resource sharing, social recognition, and contributions to the local economy. ${ }^{221}$ These arrangements can be complex, combining ownership rights or shareholdings, which both guarantee control and transparency and also generate benefits as profits and share revenue. Furthermore, shareholding arrangements are a powerful positional tool that guarantees a degree of ongoing control in an enterprise, which can support demands for participation

\footnotetext{
217 Sarah Colenbrander, David Dodman, and Diana Mitlin, 'Using Climate Finance to Advance Climate Justice: The Politics and Practice of Channelling Resources to the Local Level', Climate Policy 1 (2017).

Elisa Morgera, 'Justice, Equity and Benefit-Sharing under the Nagoya Protocol to the Convention on Biological Diversity', 24 The Italian Yearbook of International Law Online 113 (2015).

219 Barrera-Hernandez, et al., supra note 3, 8.

220 See discussion in Armeni, supra note 67, 428f.

221 Nagoya Protocol, Annex 1.
} 
in projects and the legitimate realization of benefits. Project benefits should reflect the values and priorities of the recipients and be determined with their full participation, ${ }^{222}$ and should be needed and usable by them.

It is also important that 'net' benefits are considered and calculated whatever is received should not be eclipsed by the costs and impacts of the activities on the affected community (particularly when the benefits are financial). ${ }^{223}$ The net costs should include costs of administration and management of the benefits fund, which might require professional services, but at the very least should include interest and administration charges, and may have implications for tax or other entitlements. ${ }^{224}$ For this, recipients should have a reasonable expectation of transparency in relation to project revenue and the risks and costs anticipated under the project. ${ }^{225} \mathrm{~A}$ calculation of net benefits in the context of proper administration could prevent the social disruption frequently experienced by marginalized communities which receive sudden, unstructured income. 226

As highlighted earlier, difficulties can arise in circumstances where involvement of potential beneficiaries with projects gives rise to a range of entitlements, all of which could be settled financially. A strong argument could be made that benefit-sharing arrangements have a reparative or compensatory aspect to them; ${ }^{227}$ however, the purpose of these arrangements is not to compensate or make good loss, but rather to ensure that vulnerable parties are properly remunerated and acknowledged for their role in making the project possible. For instance, IPLC resettled from their land, or who otherwise lose tenure or other rights, should be entitled to compensation or reparations for the loss of tenure rights or relocation. In addition, they might be entitled to benefit-sharing arrangements in relation to the use of their traditional knowledge

222 This understanding emanates from the 2002 Bonn Guidelines; see Vermeylen, supra note, 15,424 .

223 Schwemmer et al., supra note 55. Some models refer to this as 'sharing the burdens', aligned with 'sharing the costs'. Burden-sharing has its own meaning in climate discourse, and I do not consider it is helpful to use that wording in a different way. In addition, this does not describe well what I mean-the costs of the project to the vulnerable benefitrecipients may not necessarily be 'burdens' of the project as a whole.

This may include entitlement to state benefits or grants, such as pensions, unemployment benefits, or parental support, particularly if means-tested. These issues should be managed, and the costs of management should be incorporated into the calculation of the benefit.

226 Vermeylen and Walker, supra note 200, 119.

227 Bram De Jonge, 'What Is Fair and Equitable Benefit-Sharing?', 24 Journal of Agricultural and Environmental Ethics 127 (2011). 
or due to an infringement of residual rights. ${ }^{228}$ As discussed earlier, these distinctions should be made at an early assessment stage, but it is difficult to see how this could be managed in such a way as to ensure that the full range of available entitlements is not absorbed into other kinds of payments that might serve a different purpose..$^{229}$

Baker explains that in some instances the very design of a project obviates any possibility of benefit-sharing. In the context of renewable energy projects funded with project finance, she writes:

With the exception of payments to the Mexican government and development banks, all benefits flow exclusively to corporate actors. Indeed, the energy produced is sold to corporations ... Debt payments are made to private banks. Once the debt payments are made, profit flows up to the private developers who are the initial investors in the projects. The structure of the projects themselves impedes any hope of authentic community benefits. Proponents of the projects point to one public good: a net positive reduction in greenhouse gas emissions. ${ }^{230}$

But in less intensively structured arrangements, the design of financing instruments is worth investigating in terms of what might be understood to be the 'benefits' arising from a project. This cannot be separated from a discussion about the ultimate direction of flows of climate finance.

Interest earned on supported concessional loans, and both capital and equity earned through supported investments, are clear monetary benefits generated in climate-specific situations with the support of (largely publicly funded) climate funds. In this sense, public climate finance supports the creation of a viable, risk-managed market for the providers of private finance, which generates financial benefits for them. Apart from the climate benefits, in commercial terms the provision of finance is only beneficial to the recipients. These processes and arrangements raise all sorts of questions about mutual interest and the possibility of shared benefits. If anything, financing arrangements are inherently associated with the provision of climate finance than the various recipient-end projects that are funded by it. Of course, the counterargument is clear: that there is no appropriate 'benefit-sharing' trigger in

228 For instance, see Herrejon and Savaresi, supra note 53.

229 For instance, Craik, Gardner, and McCarthy, supra note 49, discuss how natural-resource agreements stipulate that impact mitigation and benefits should be dealt with separately; see $381-3$.

Baker, supra note 62 , 35 . 
these instances, and that benefit-sharing arrangements are appropriate (and required) in relation to the receipt of climate finance, not its provision.

\subsection{Triggers}

There should be clearly defined conditions that would trigger benefit-sharing obligations. ${ }^{231}$ Establishing clear triggers for benefit-sharing would help to clarify why benefits generated in certain contexts give rise to obligations to ensure equitable access, but not benefits generated in others. The different approaches and rationales taken will affect conceptions of the benefit as well as the trigger. But the determinations of benefit-sharing based on markets and resource use, impacts, and human rights, or co-operation within projects, will determine to some extent when and how such projects are framed, who is considered a stakeholder, and how benefit-sharing arrangements would be constructed around them. ${ }^{232}$ Having clear and mandatory triggers means that less is left to chance or the discretion of decision-makers or applicants.

\section{5}

\section{Conclusion}

I have argued that benefit-sharing is an emerging norm in international environmental law and human rights law. Broadly stated, benefit-sharing is meant to provide a means towards fair and equitable distribution of burdens and benefits - and, as such, the achievement of practical justice - in environmental and natural-resource use. Despite problems in application and implementation, benefit-sharing continues to be introduced into new areas of international environmental law, but with differing and varied conceptualizations and mixed results.

This article contributes to the small pool of literature which seeks to examine how benefit-sharing appears in climate change, and offers the first discussion of benefit-sharing in climate finance. ${ }^{233}$ The heterogeneous nature of climate finance, and the conceptual and normative challenges in establishing a norm of benefit-sharing, make this a difficult area of enquiry. A more self-contained endeavour may have sought simply to identify the formal obligations in this area; however, doing so without exploring some of the difficult questions

\footnotetext{
231 See discussion in Morgera, supra note 41, 372f.

232 Ibid., 379-8o.

233 By 'specific' I mean focusing on climate finance per se, as opposed to considering topics tangential to climate finance.
} 
arising in the messy field of benefit-sharing more generally would have been to ignore the difficult richness of this area.

I have sought to clarify the basis on which benefit-sharing might be read as an obligation in international climate change and climate finance law, but one that lacks substantive content. This article appraised the arguments for and against a more developed concept, arguing that despite the implementation problems reported in benefit-sharing in other areas of international environmental law, the concept is likely to continue to be used to distribute benefits in climate-response activities. In many ways, benefit-sharing is not an easy fit for climate finance, but drawing on standards and research in other areas of international law, including human rights law, can help to flesh out some core requirements as to how benefit-sharing can be better conceptualized in climate finance. For this reason, attention is needed in terms of how benefit-sharing is deployed in the climate change field. Starting with an investigation of the climate funds, this article has suggested that current practice in climate finance has not kept pace with international minimum standards on benefit-sharing.

Finally, notwithstanding the difficulties and complexities explored herein, I have sought to outline some factors that would need to be considered in developing a norm of benefit-sharing in climate finance, which is specific to the area, but also keeps pace with international standards. 